\title{
Climate Change Prompts Monitoring and Systematic Utilization of Honey Bee Diversity in Turkey
}

\author{
Mert Kükrer $^{1,2, *} \mathbb{D}^{\mathbb{D}}$, C. Can Bilgin ${ }^{1}$ \\ ${ }^{1}$ Middle East Technical University, Biology Department, Ankara, Turkey \\ ${ }^{2}$ Kilis 7 Aralik University, Molecular Biology and Genetics Department, Kilis, Turkey
}

\section{Article History}

Received 06 June 2020

Accepted 28 July 2020

First Online 31 July 2020

\section{*Corresponding Author \\ Tel.: +905077069149 \\ E-mail: mertkukrer@gmail.com}

\section{Keywords}

Global change

Adaptive capacity

Long-term monitoring

Whole genome sequencing

Natural selection

\begin{abstract}
Quantitative studies concerning the impact of climate change on pollinators are generally lacking. Relationship between honey bee diversity, present local adaptations and adaptive capacity of subspecies and ecotypes in the face of climate change is an urgent but rather poorly studied topic worldwide. Actually, such an effort lies at the crossroads of various fields of inquiry. Those include conservation of local honey bee diversity, breeding various local stocks for desirable traits, and enabling resilient ecosystem services. With the ever-increasing availability of genomic tools, now it is more probable than ever to simultaneously fill such gaps. Current knowledge and growing awareness on honey bee diversity in Turkey let us progress into a more systematic utilization of this resource through development of climate-conscious models. Here we provide a framework that takes genomic diversity into account for assessing and monitoring various aspects of species' response to climate change which can potentially lead to drastic impacts.
\end{abstract}

\section{Introduction}

As the global environment alters with an increasing pace, ecosystem resilience becomes more reliant on the readjustment of species to emerging conditions. For this reason, it is important to evaluate, monitor and manage genetic diversity and related adaptation capacity based on scientific results. Given the possible angular effects of climate change in the upcoming decades, it is necessary to expose how ecosystems can benefit from genetic diversity. In addition, it is essential to develop and test best practice protocols to monitor genetic diversity that varies in space and time.

In terms of honey bee (Apis mellifera) biodiversity, the current direction of anthropogenic impact is in line with the loss of native races and the adaptations they have accumulated over thousands of years (de la Rúa et al., 2013; Jensen, Palmer, Boomsma, \& Pedersen, 2005;
Soland-Reckeweg, Heckel, Neumann, Fluri, \& Excoffier, 2009). The factors that cause colony losses in honey bees are very diverse. Possible loss or decline of pollinators are thought to be due to a combined result of destruction and degradation of habitats, pollution and pesticide related toxicity, pathogen and parasite related diseases, and invasive species many of which also effect honey bees (de la Rua, Jaffé, Dall'Olio, Muñoz, \& Serrano, 2009; Goulson, Nicholls, Botías, \& Rotheray, 2015; Potts et al., 2010; van der Zee, Gray, Pisa, \& de Rijk, 2015).

Increasing hybridization of honey bee subspecies due to human activities like migratory beekeeping and queen and colony trade also threaten honey bees by potentially leading to loss of gene combinations that provide local success (Kükrer, Kence, \& Kence, 2020). The absence of effective implementation of documentation and monitoring methods for uncovering 
the genetic basis of adaptive traits makes it difficult to understand and resist the trend of human induced loss of adaptive diversity. However, it is not possible to achieve success in long-term monitoring especially, without developing methods that are inexpensive and feasible but still able to provide meaningful data by deployment of technology-intensive procedures.

New risks and challenges are causing concern as global climate change potentially elevate temperatures and aridity in many parts of the world. We have very little information - not only in Turkey but in the world about the overall impact of climate change on honey bees, even less on pollinators as a whole. However, most predictions suggest that climate change will worsen the situation by introducing new stressors (González-Varo et al., 2013; le Conte \& Navajas, 2008).

A reduction in adaptive genetic diversity will not only be loss of a historic natural heritage that is intrinsically valuable but also of various economic and ecological benefits for the society (Espregueira et al., 2020). Urgently focusing on the genomic analysis of the relationship of honey bees with their environment in the era of global climate change will be to the benefit of both the society and the nature. There is now a strong incentive to consider and investigate pronounced influences of environmental conditions on honey bees through a perspective of ecosystem resilience.

This article aims to emphasize the need for developing a framework that takes genomic diversity into account for monitoring the adaptive capacities of honey bee subspecies and ecotypes present in Turkey in response to climate change.

\section{It is Not Known in What Way the Global Climate Change Will Affect Honey Bee Populations}

It is predicted that Turkey's climate will in general become hotter and more arid (Bilgin \& Türkeş, 2008; Bilgin, 2013). However, the impact of this change on ecosystems and species still needs to be explored. It is of decisive importance whether the pollinators in general and honey bees in particular can adapt to a rapidly changing environment due to their role in nature and agricultural activities. However, our knowledge of the adaptation capacities in those species is limited. In addition to the identification of genes taking a role in adaption to hot and dry environments, documenting the existence and distribution of such genes in honey bee populations is important too.

Beyond single genes, the distribution of subspecies is determined under the influence of various climatic, geographical and biological factors. These complex factors can be combined to model the subspecies' ecological niches whose long-term characteristics will retain themselves under natural selection (Peterson, 2003). It is not always true that the combination of environmental conditions in which the species can survive is limited only by the current distribution of the species. Therefore, when it comes to modeling the distribution of a species, it is also necessary to refer to the basic niche, realized niche and potential niche concepts (Sillero, 2011).

Such models can be used not only to explain the current situation but also to model the distributions in the past - especially in the ice ages during which subspecies were drawn to refuges (Kozak, Graham, \& Wiens, 2008). If a precise population genetic structure map can be generated based on genome surveys making use of high-density SNP data it might be possible to clarify how current distributions of the subspecies are affected by historical processes.

Similar models can be used to predict how species and sub-species would react under various climate change scenarios (Fordham, Akçakaya, Araújo, Keith, \& Brook, 2013). Findings to be obtained in this way are good candidates as contributions to conservation planning, since they provide hints about how ecologically and economically important gene resources may change in the future.

There is no doubt of the various difficulties in terms of distribution modeling in species that interact with humans. However, these difficulties do not create insurmountable obstacles. For example, in the case of honey bee subspecies, the fact that these can be transported by people from one region to another would even be useful, as it will facilitate understanding of the potential niche (Jimenez-Valverde et al., 2011).

Of course, the purpose of creating models related to climate change cannot be to make definitive judgments about distributions, especially for species that humans utilize. The main purpose should be to reveal the stress factors and selection pressures that will occur in future ranges. Ecological niche models assist in determining relative weights of a wide variety of climatic and geographical factors that will require adaptation or species' adaptive capacities.

There is already evidence that the current climate might be playing a role in the distribution of honey bee subspecies. Separate studies in the Carpathians and on Africanized bees in South America indicate that borders of the subspecies might be determined by their capacity to adapt to vital factors such as temperature and precipitation (Coroian et al., 2014; Nelson, Wallberg, Simões, Lawson, \& Webster, 2017). This is in contrast to artificial selection efforts by humans which are not mainly related to climate and geography, but rather agricultural characteristics such as yield and disease resistance.

Considering that honey bees have an intense interaction with the environment, it is almost impossible to think that they would not be affected by climate change. Therefore, the detection of genes that may prove to be useful in adapting climate change and investigating the effects of this change on the distribution of subspecies and ecotypes would fill an important gap. 
Unique Adaptations of Honey Bees in Turkey Are Not Studied at the Genome Level

Migratory beekeeping and bee trade are shown to act like a hybrid zone mobile in space and time, facilitating the partial amalgamation of subspecies in Turkey (Kükrer, 2013; Kükrer et al., 2020; Oskay, Kükrer, \& Kence, 2019). Despite that, high levels of geographically structured genetic diversity of honey bee subspecies in Turkey and the need to develop policies to maintain it, was also confirmed.

But how can the natural population genetic structure be preserved, when about 5 million of the 8 million hives in Turkey are taken from one region to another each year, and tens of thousands of queen bees change hands? Could environmental consequences play a certain role in the maintenance of distinct subspecies? In order to find answers, it should be examined whether there is a relationship between the distribution of various geographical and climatic factors such as temperature, humidity, altitude, precipitation regime, winter severity, insolation, flora, and the current distribution of subspecies. It can also be tested which particular genetic features obtained from whole genome sequencing change in a clinal fashion in line with environmental factors (Jones et al., 2013).

If honey bee populations are subject to natural selection due to their environment, then this selection force would emerge as a stabilizing factor for preserving locally adapted subspecies by acting against hybrids, and eventually restricting gene flow between populations (Feder \& Nosil, 2010). In that case, natural selection would counterweigh the effect of gene flow between populations and random genetic drift. As a result, it is inevitable to observe different combinations of allele frequencies in various populations (Savolainen, Lascoux, \& Merilä, 2013). Sudden changes are to be expected where selection is relatively strong while a smoother transition would be observed in regions where gene flow between populations is higher (Beekman, Allsopp, Wossler, \& Oldroyd, 2008).

Since random genetic drift increases the differentiation between populations isolated from each other, the effects of geographical barriers also become measurable. In cases where a certain climatic factor or selection is not causative, it should be considered that the significant genetic distance between populations depends on geographical isolation (Manel, Schwartz, Luikart, \& Taberlet, 2003).

The functions of the DNA regions candidates for selection can be easily inferred since honey bee genome was sequenced at an early stage and is studied relatively well (The Honey Bee Genome Sequencing Consortium, 2006). Therefore, it is possible to investigate the relationship between selected genes and environmental factors. At this stage, the goal is to make biologically meaningful inferences about the functions of any candidate genes selected in relation to climatic and geographical variables.
In a recent study on the relationship between environmental conditions and genome-wide selection, it has been observed that altitude-related adaptations are preserved in two African subspecies where gene flow between them is so intense that it prevents observation of a genetic structure (Wallberg, Schöning, Webster, \& Hasselmann, 2017). It is normal to expect a similar process in Turkey where adaptations to environmental factors were preserved despite high levels of gene flow. In another study from Kenya, genes that could play an important role in adaptation to various climate types and geographies were investigated by comparing savanna, coastal, mountain and desert populations (Fuller et al., 2015). In a research conducted on a newly identified subspecies in China, researchers focused on the genetic effects created by transition from tropics to the temperate zone (Chen et al., 2016). In the Iberian Peninsula where genome-wide selection signals based on bioclimatic variables were investigated (Henriques et al., 2018) the findings demonstrate that genes involved in regulation of the biological clock by biosynthesis of macromolecules are associated with local adaptations.

Concerning honey bee subspecies in Turkey, various studies making use of SNP markers in honey bees have been carried out in the past. Whitfield et al. (2006) included samples from Turkey in their research, but this work was essentially in the domain of phylogeography. Although 11 genes were identified as candidates for selection, that comparison was carried out on Italian, Western European and African bees but bees from Turkey were excluded from that part of the study. Wallberg et al. (2014) focused on local adaptations but samples obtained from Turkey were only evaluated for extraction of global population structure. Here, the main comparison was made between A-C, A-M and C-M lineages leaving aside Olineage bees which also includes subspecies in Turkey. Cridland, Tsutsui, and Ramírez (2017), did not themselves gather samples from Turkey but made use of data generated by Wallberg et al. (2014). Uncertainties caused by a sequencing method that is no longer available due to high error rates were revealed and the need for analysis of high-quality genome data belonging to samples from Turkey and South West Asia was emphasized.

Although different aspects of genetic diversity of honey bee subspecies in Turkey were examined, the way they are adapted to the local conditions were not studied at the genome level. In addition, despite extensive research, the exact distributional ranges of the subspecies and the core areas where they are found in "pure" forms are still not clear. This also holds for regions where subspecies' ranges overlap and they exchange genes with each other, as well as for critical regions where sudden changes in the subspecies composition occur.

It is possible that these deficiencies would be eliminated with a well-planned countrywide study which, in this way, would lead to a better understanding 
of genetic resources of native honey bee races and provide the most basic information that could be utilized in breeding efforts. Bearing in mind the global climate change, uncovering how climate and geography affect honey bees will be vital for the success of future breeding and conservation projects.

\section{There is No Model Yet to Monitor Honey Bee Genetic Diversity in Turkey}

In Turkey, within the last decade, awareness about the potential value of the honey bee diversity has radically improved due to intensive efforts of scientists, beekeepers' associations and civil society organizations. In parallel, there has been an increase in conservation implementations and rehabilitation in the field of honey bee ecotypes (Gül, 2020). Currently, breeding herds are either being created or have already been established in Ankara, Ardahan, Artvin, Çanakkale, Çorum, Düzce, Hatay, İzmir, Kırklareli, Kırşehir and Muğla provinces. Since these activities are aimed at local ecotypes, important genetic material is thus put under protection. In concordance with these efforts, a number of subspecies and ecotypes are in the process of being registered by The Ministry of Agriculture and Forestry as native genetic resources of Turkey. This action, too, can be expected to contribute to conservation and breeding efforts in Turkey.

Monitoring programs are implemented in order to detect changes in genetic variability or in the frequencies and the distribution of adaptive variants (Flanagan, Forester, Latch, Aitken, \& Hoban, 2018). It is possible now, to further enhance the valuable steps taken till the moment and start monitoring of honey bee genetic diversity in Turkey and to consider making use of emerging technological tools in the field of genome sequencing as well as the decreasing costs.

However, till now, methods used for discrimination of subspecies in such efforts are mainly based on morphology, geometric morphometry and on mitochondrial as well as nuclear DNA markers like microsatellites. Resolution provided by such methods are far from precise discrimination of ecotypes, let alone allowing accurate reflection of diversity present in Turkey. Furthermore and more importantly, they do not let us to take into account a conscious incorporation of genomic elements that play role in adaptation of ecotypes to their natural environment. Today conservation and breeding efforts should focus more on genetic variation specifically improving the subspecies' capacity to adapt climate change. Constraints related to the adequate documentation of genetic diversity in Turkey do not enable yet, the development of functional and at the same time low-cost monitoring models.

An adaptive management context with an integrated monitoring step will enjoy the chances of both learning more about the local ecotypes and evaluating the effectiveness of management actions once they are initiated. After an initial genomic assessment by sequence capture methods or SNP arrays, it is possible to consistently genotype many individuals over time. This would certainly help to reach diverse objectives like diagnosing introgression and conservation efficacy, characterization of neutral and adaptive genetic variation especially related to climate change, as well as retrieving information about desirable traits (Aykanat, Lindqvist, Pritchard, \& Primmer, 2016).

\section{A Potent Long-Term Ecological Research Perspective and Scope}

Basically, any research addressing the adaptive capacities of subspecies in Turkey against climate change should cover the following scope:

(i) Core regions in which 5 honey bee subspecies stay unmixed should be identified by an intense sampling effort across the country from stationary apiaries whose beekeepers reject to replace queens and colonies with non-native races. In order to achieve this, genome-wide data obtained with next generation sequencing techniques should be utilized.

(ii) Despite the anthropogenic impact in the form of migratory beekeeping and trade, subspecies are known to preserve their identities at certain places. Selection at the genomic level naturally relies on environmental conditions. Investigation of this phenomenon necessarily means comparing relative weights of natural selection, gene flow and genetic drift within populations.

(iii) Candidate genes located in genome regions under selection and playing a role in adaptation to local conditions should be identified. The functions of these genes and their relation with the environmental conditions should be examined. Genetic features that play a role in adaptation to elevated temperatures and aridity should be revealed through various comparisons between populations residing in such milieu. Existing conservation and breeding efforts like those supported and carried out by The Ministry of Agriculture and Forestry and Turkish Beekeepers' Association should better be reinforced by evolutionary knowledge. This will be achieved through purposeful introduction of locally adaptive genetic variants in addition to variants that provide adaptive potential under climate change within such stocks.

(iv) In order to preserve the genetic diversity and adaptation capacities documented in this way, a lowcost, feasible, but technology-intensive monitoring method should be developed. After an initial assessment, intensive sampling coupled with monitoring of conservation areas for these alleles by at least 5-year intervals should be guaranteed.

(v) Population structure obtained from genetic data should be used in models that will shed light on the evolutionary histories of subspecies and how their natural distribution would be affected under various global climate change scenarios. 


\section{Discussion}

The most important needs of the actual period include the establishment of quantitative and regular implementations to appraise, monitor and manage the genetic resilience and adaptive capacity for species under human use or those not. This points to relevance for incorporation of genetic and evolutionary knowledge in policies concerning conservation planning and sustainability of ecosystem services, particularly under the severe impact of global climate change (COST Committee of Senior Officials, 2018).

The challenges faced in this area can be more easily overcome via piecing together of the following pursuit, akin but not limited to providing integration platforms in order to link together stakeholders and developing collaborations that combine experience in various areas of expertise to form the basis of a sustainable impact as well as integrating emerging technological tools into existing activities; explaining decision-makers how genetic diversity can benefit ecosystems; developing and testing best practice protocols for monitoring genetic diversity in space and time. As a key pollinator, honey bees (Apis mellifera) draw much attention among species aimed for determination and monitoring of the genetic adaptation capacities in response to climate change.

Although honey bees are intensively managed by humans, they cannot be regarded as fully domesticated. Apart from wild populations in the natural distribution range of the species or feral colonies that escaped from human hands, even colonies under human control act as part of wildlife due to nectar and pollen foraging activities. Their unique role in pollination makes bees a critical species for ecosystem resilience in addition to agricultural production and ecosystem services.

We need to put forward a monitoring model that can process honey bee diversity throughout the country. This also provides an opportunity to go beyond a general characterization of biodiversity. It can be aimed to monitor, in terms of presence and distribution, both specific alleles involved until now in local adaptation to native conditions and also genetic features that may contribute to adaptive potential under conditions of global climate change.

Long-term monitoring is a costly and laborintensive process. This is also the most important reason for the fact that monitoring studies with a large spatial scale are not always possible. A technology-intensive monitoring model that combines the most costeffective, feasible, state-of-the-art scientific methods developed and tested till now is likely to contribute to the goal of creating standard and routine tools.

Developing a model for monitoring and utilization of honey bee genomic diversity is not only useful for revealing the adaptive potential to climate change, but also with simple customizations, would provide new opportunities for implementation of marker assisted selection in breeding for disease resistance (varroosis,
Nosema, foulbrood, etc.), obtaining desirable phenotypic characters (gentleness, wintering success, low swarming tendency, etc.) and increased yield (honey, royal jelly, pollen, propolis, bee venom and other bee products).

Genomic diversity and adaptive potentials are rapidly lost or undergoing serious changes under human influence. With such a model, decision-makers and field operators might have a chance to benefit from genomic and evolutionary information in the face of adverse human-induced effects.

This piece focuses on the limits of our knowledge on honey bee diversity in Turkey, its interaction with the environment, the consequences of this interaction for natural selection, and its implications for the future under global climate change. We recommend that further research in honey bee genetics would better seek previously unexplored phenomenon, structures and relationships. Such investigation would have the potential to innovatively apply to the situation the knowledge and techniques in the field of genomics and to contribute in the formation of an understanding that will be utilized in a way which may concern many stakeholders.

\section{Acknowledgments}

This study was funded by Middle East Technical University Revolving Funds (project no: 2007-16-12-003008).

\section{References}

Aykanat, T., Lindqvist, M., Pritchard, V.L., \& Primmer, C.R. (2016). From population genomics to conservation and management: a workflow for targeted analysis of markers identified using genome-wide approaches in Atlantic salmon Salmo salar. Journal of Fish Biology, 89, 2658-2679. doi:10.1111/jfb.13149

Beekman, M., Allsopp, M. H., Wossler, T. C., \& Oldroyd, B. P. (2008). Factors affecting the dynamics of the honey bee (Apis mellifera) hybrid zone of South Africa. Heredity, 100(1), 13-18. http://doi.org/10.1038/sj.hdy.6801058

Bilgin, C. C., \& Türkeş, M. (2008). Turkey Country Report. In: R. Laušević, L. Jones-Walters, A. Nieto \& A. Torre-Marín (Eds.), Climate change and biodiversity in South-East Europe: a concise summary of the scientific and policy context, issues and recommended actions (pp. 50-55). REC, Szentendre, Hungary; ECNC, Tilburg, the Netherlands

Bilgin, C.C. (2013). Türkiye'nin doğası iklim değişikliğinden nasıl etkilenecek? ODTÜ SEM Dönem Arası Seminerleri, 29-31 Ocak 2013, Ankara.

Chen, C., Liu, Z., Pan, Q., Chen, X., Wang, H., Guo, H., ... \& Shi, W. (2016). Genomic analyses reveal demographic history and temperate adaptation of the newly discovered honey bee subspecies Apis mellifera sinisxinyuan n. ssp. Molecular Biology and Evolution, 33(5), 1337-1348.

Coroian, C.O., Muñoz, I., Schlüns, E.A., Paniti-Teleky, O.R., Erler, S., Furdui, E.M., ... \& Moritz, R.F. (2014). Climate rather than geography separates two European honey bee subspecies. Molecular Ecology, 23(9), 2353-2361. 
COST Committee of Senior Officials, (2018). Memorandum of Understanding for the implementation of the COST Action "Genomic Biodiversity Knowledge for Resilient Ecosystems" (G-BIKE) CA18134. https://eservices.cost.eu/files/domain_files/CA/Action_CA18134 /mou/CA18134-e.pdf

Cridland, J. M., Tsutsui, N. D., \& Ramírez, S. R. (2017). The complex demographic history and evolutionary origin of the western honey bee, Apis mellifera. Genome Biology and Evolution, 9(2), 457-472.

De la Rua, P., Jaffé, R., Dall'Olio, R., Muñoz, I., \& Serrano, J. (2009). Biodiversity, conservation and current threats to European honey bees. Apidologie, 40(3), 263-284.

De la Rúa, P., Jaffé, R., Muñoz, I., Serrano, J., Moritz, R.F.A., \& Kraus, F.B. (2013). Conserving genetic diversity in the honeybee: Comments on Harpur et al. (2012). Molecular Ecology, 22, 3208-3210. doi:10.1111/mec.12333

Espregueira, G., Rey-Iglesia, A., Robles Tascón, L., Jensen, A.B., da Fonseca, R., \& Campos, P.F. (2020). Declining genetic diversity of European honeybees along the twentieth century. Scientific Reports, 10, 105-120. https://doi.org/10.1038/s41598-020-67370-2

Flanagan, S. P., Forester, B. R., Latch, E. K., Aitken, S. N., \& Hoban, S. (2018). Guidelines for planning genomic assessment and monitoring of locally adaptive variation to inform species conservation. Evolutionary Applications, 11, 1035-1052. https://doi.org/10.1111/ eva.12569

Feder, J.L., \& Nosil, P. (2010). The efficacy of divergence hitchhiking in generating genomic islands during ecological speciation. Evolution, 64(6), 1729-1747.

Fordham, D.A., Akçakaya, H.R., Araújo, M.B., Keith, D.A., \& Brook, B.W. (2013). Tools for integrating range change, extinction risk and climate change information into conservation management. Ecography, 36(9), 956-964. http://doi.org/10.1111/j.1600-0587.2013.00147.x

Fuller, Z.L., Niño, E.L., Patch, H.M., Bedoya-Reina, O.C., Baumgarten, T., Muli, E., ... \& Masiga, D. (2015). Genome-wide analysis of signatures of selection in populations of African honey bees (Apis mellifera) using new web-based tools. BMC genomics, 16(1), 518.

González-Varo, J. P., Biesmeijer, J. C., Bommarco, R., Potts, S. G., Schweiger, O., Smith, H. G., ... \& Vilà, M. (2013). Combined effects of global change pressures on animalmediated pollination. Trends in Ecology \& Evolution, 28(9), 524-530.

Goulson, D., Nicholls, E., Botías, C., \& Rotheray, E. L. (2015). Bee declines driven by combined stress from parasites, pesticides, and lack of flowers. Science, 347(6229).

Gül, A. (2020). Islah çalışmalarımız: “Türkiye'de Bulunan Bazı Arı (Apis mellifera L.) Irk ve Genotiplerini Temsil Eden Kolonilerin Orijinal Alanlarında Morfolojik ve Moleküler Karakterizasyonu ve Belirli Karakterler Yönünden İyileştirilmesi" projesi. TAB Arıcılık Dergisi, 3, 8-9.

Henriques, D., Wallberg, A., Chávez-Galarza, J., Johnston J., Webster M., \& Pinto M. (2018). Whole genome SNPassociated signatures of local adaptation in honey bees of the Iberian Peninsula. Scientific Reports, 8(1), 11145. doi: 10.1038/s41598-018-29469-5.

Honey Bee Genome Sequencing Consortium (2006). Insights into social insects from the genome of the honey bee Apis mellifera. Nature, 443(7114), 931-949. https://doi.org/10.1038/nature05260

Jensen, A. B., Palmer, K. A., Boomsma, J. J., \& Pedersen, B. V. (2005), Varying degrees of Apis mellifera ligustica introgression in protected populations of the black honeybee, Apis mellifera mellifera, in northwest Europe. Molecular Ecology, 14, 93-106. doi:10.1111/j.1365294X.2004.02399.x

Jiménez-Valverde, A., Peterson, A.T., Soberón, J., Overton, J. M., Aragón, P., \& Lobo, J. M. (2011). Use of niche models in invasive species risk assessments. Biological Invasions, 13(12), 2785-2797.

Jones, M.R., Forester, B.R., Teufel, A.I., Adams, R.V., Anstett, D.N., Goodrich, B.A., ... Manel, S. (2013). Integrating landscape genomics and spatially explicit approaches to detect loci under selection in clinal populations. Evolution, 67(12), 3455-3468. http://doi.org/10.1111/ evo.12237

Kozak, K.H., Graham, C.H., \& Wiens, J.J. (2008). Integrating GISbased environmental data into evolutionary biology. Trends in Ecology and Evolution, 23(3), 141-148. http://doi.org/10.1016/j.tree.2008.02.001

Kükrer, M. (2013). Genetic diversity of honey bee populations in Turkey based on microsatellite markers: a comparison between migratory versus stationary apiaries and isolated regions versus regions open to migratory beekeeping (MSc. Thesis), METU, Ankara, Turkey.

Kükrer, M., Kence, M., \& Kence, A. (2020). Honey Bee Diversity is Swayed by Migratory Beekeeping and Trade Despite Conservation Practices: Genetic Evidences for the Impact of Anthropogenic Factors on Population Structure. bioRxiv doi: 10.1101/154195

Le Conte, Y., \& Navajas, M. (2008). Climate change: impact on honey bee populations and diseases. Revue Scientifique et Technique-Office International des Epizooties, 27(2), 499-510.

Manel, S., Schwartz, M. K., Luikart, G., \& Taberlet, P. (2003). Landscape genetics: Combining landscape ecology and population genetics. Trends in Ecology and Evolution, 18(4), 189-197. http://doi.org/10.1016/S0169-5347(03) 00008-9

Nelson, R.M., Wallberg, A., Simões, Z.L.P., Lawson, D.J., \& Webster, M.T. (2017). Genome-wide analysis of admixture and adaptation in the Africanized honey bee. Molecular Ecology, 26(14), 3603-3617.

Oskay, D., Kükrer, M., \& Kence, A. (2019). Muğla bal arısında (Apis mellifera anatoliaca) Amerikan yavru çürüklüğü hastalığına karşı direnç geliştirilmesi. Arıcılık Araştırma Dergisi, 11(1), 8-20.

Peterson, A.T. (2003). Predicting the geography of species' invasions via ecological niche modeling. The quarterly review of biology, 78(4), 419-433.

Potts, S.G., Biesmeijer, J.C., Kremen, C., Neumann, P., Schweiger, O., \& Kunin, W.E. (2010). Global pollinator declines: trends, impacts and drivers. Trends in Ecology \& Evolution, 25(6), 345-353.

Savolainen, O., Lascoux, M., \& Merilä, J. (2013). Ecological genomics of local adaptation. Nature Reviews. Genetics, 14(11), 807-820. http://doi.org/10.1038/nrg3522

Sillero, N. (2011). What does ecological modelling model? A proposed classification of ecological niche models based on their underlying methods. Ecological Modelling, 222(8), 1343-1346.

Soland-Reckeweg, G., Heckel, G., Neumann, P., Fluri, P., \& Excoffier L. (2009). Gene flow in admixed populations and implications for the conservation of the Western honeybee, Apis mellifera. Journal of Insect Conservation, 13, 317. https://doi.org/10.1007/s10841-008-9175-0 
Van der Zee, R., Gray, A., Pisa, L., \& de Rijk, T. (2015). An Observational Study of Honey Bee Colony Winter Losses and Their Association with Varroa destructor, Neonicotinoids and Other Risk Factors. PLOS ONE, 10(7), e0131611.https://doi.org/10.1371/journal.pone.01316 11.

Wallberg, A., Han, F., Wellhagen, G., Dahle, B., Kawata, M., Haddad, N., ... Webster, M. T. (2014). A worldwide survey of genome sequence variation provides insight into the evolutionary history of the honey bee Apis mellifera.
Nature Genetics, 46(August), 1081-1088. http://doi.org/10.1038/ng.3077.

Wallberg, A., Schöning, C., Webster, M. T., \& Hasselmann, M. (2017). Two extended haplotype blocks are associated with adaptation to high altitude habitats in East African honey bees. PLoS Genetics, 13(5), e1006792.

Whitfield, C. W., Behura, S. K., Berlocher, S. H., Clark, A. G., Johnston, J. S., Sheppard, W. S., ... Tsutsui, N. D. (2006). Thrice out of Africa: ancient and recent expansions of the honey bee, Apis mellifera. Science, 314(5799), 642-645. http://doi.org/10.1126/science.1132772. 
